\title{
TU/e EmonOWEN

\section{Oxytocin levels in the saliva of preterm infant twins during Kangaroo care}

\section{Citation for published version (APA):}

Kommers, D., Broeren, M., Oei, G., Feijs, L., Andriessen, P., \& Bambang Oetomo, S. (2018). Oxytocin levels in the saliva of preterm infant twins during Kangaroo care. Biological Psychology, 137, 18-23.

https://doi.org/10.1016/j.biopsycho.2018.06.009

\section{Document license: \\ TAVERNE}

DOI:

10.1016/j.biopsycho.2018.06.009

Document status and date:

Published: 01/09/2018

\section{Document Version:}

Publisher's PDF, also known as Version of Record (includes final page, issue and volume numbers)

\section{Please check the document version of this publication:}

- A submitted manuscript is the version of the article upon submission and before peer-review. There can be important differences between the submitted version and the official published version of record. People interested in the research are advised to contact the author for the final version of the publication, or visit the $\mathrm{DOI}$ to the publisher's website.

- The final author version and the galley proof are versions of the publication after peer review.

- The final published version features the final layout of the paper including the volume, issue and page numbers.

Link to publication

\section{General rights}

Copyright and moral rights for the publications made accessible in the public portal are retained by the authors and/or other copyright owners and it is a condition of accessing publications that users recognise and abide by the legal requirements associated with these rights.

- Users may download and print one copy of any publication from the public portal for the purpose of private study or research.

- You may not further distribute the material or use it for any profit-making activity or commercial gain

- You may freely distribute the URL identifying the publication in the public portal.

If the publication is distributed under the terms of Article 25fa of the Dutch Copyright Act, indicated by the "Taverne" license above, please follow below link for the End User Agreement:

www.tue.nl/taverne

Take down policy

If you believe that this document breaches copyright please contact us at:

openaccess@tue.nl

providing details and we will investigate your claim. 


\title{
Oxytocin levels in the saliva of preterm infant twins during Kangaroo care
}

\author{
D. Kommers ${ }^{\mathrm{a}, \mathrm{b}, *}$, M. Broeren ${ }^{\mathrm{c}}$, G. Oei ${ }^{\mathrm{d}, \mathrm{e}}$, L. Feijs ${ }^{\mathrm{f}}$, P. Andriessen ${ }^{\mathrm{a}}$, S. Bambang Oetomo ${ }^{\mathrm{a}, \mathrm{f}}$ \\ a Department of Neonatology, Máxima Medical Centre Veldhoven, The Netherlands \\ ${ }^{\mathrm{b}}$ Department of Applied Physics, Eindhoven University of Technology, The Netherlands \\ ${ }^{c}$ Clinical Chemistry Laboratory, European Specialist in Laboratory Medicine, Máxima Medical Centre Veldhoven, The Netherlands \\ d Department of Electrical Engineering, Eindhoven University of Technology, The Netherlands \\ e Department of Gynaecology, Máxima Medical Centre Veldhoven, The Netherlands \\ ${ }^{\mathrm{f}}$ Department of Industrial Design, Eindhoven University of Technology, The Netherlands
}

A R T I C L E I N F O

\section{Keywords:}

Preterm infants

Oxytocin

Saliva

Kangaroo care

Parent-infant bonding

Neonatal intensive care unit

\begin{abstract}
A B S T R A C T
Background and purpose: To investigate whether Kangaroo care (KC) influences the salivary oxytocin (OT) concentration in preterm infants, and which correlates affect the OT response.

Methods: Eleven twin pairs participated in a study in which we collected saliva using cotton swabs twice a day, once during KC and once during baseline conditions (lying in bed or incubator). The total study duration was five days. The saliva of twin siblings were pooled to obtain vials with sufficient volumes of either saliva collected during KC or at baseline. OT levels were measured using a radio-immuno assay. The infants' state of comfort and parent-infant interaction were examined using previously developed Likert-scales, amongst other correlates such as the KC duration, gestational age and birth weight.

Results: During KC, OT was lower compared to baseline (mean $1.39 \mathrm{pg} / \mathrm{ml}$ (SD $0.58 \mathrm{pg} / \mathrm{ml}$ ) versus $2.40 \mathrm{pg} / \mathrm{ml}$ (SD $1.64 \mathrm{pg} / \mathrm{ml}), p=0.03$ ). Comfort at baseline and parent-infant interaction seemed to influence OT responses. Conclusion: The OT concentration in the pooled saliva of preterm infant twins decreased during KC. This response of the OT system might be explained by stress during baseline.
\end{abstract}

\section{Introduction}

Oxytocin (OT) is a centrally synthesized peptide of nine amino acids that is critically involved in aspects of mammalian parturition, milk letdown, and social behavior (Macdonald \& Macdonald, 2010). The concentration of OT receptors increases in the myometrium of pregnant women and reaches a maximum in early labor (Fuchs, Fuchs, Husslein, Soloff, \& Fernström, 1982). Amongst other neurochemical changes, parturition causes a central OT release inducing maternal behavior, and an olfactory bulb release facilitating specific newborn-odor recognition by modulating noradrenaline, acetylcholine and gamma-aminobutyric acid release which are primary regulators for olfactory memory (Levy, Kendrick, Goode, GuevaraGuzman, \& Keverne, 1995). In the postnatal phase, differences in OT receptor levels are associated with variation in licking and grooming behavior of rat dams toward their pups and these differences are context dependent (Bartz, Zaki, Bolger, \& Ochsner, 2011; Francis, Champagne, \& Meaney, 2000). In a threatening or stressful environment OT can generate different responses (e.g. protective) compared to in a familiar environment (e.g. grooming or explorative) (Bartz et al., 2011; Neumann, 2002). It is therefore assumed to be important for parent-infant bonding (Galbally, Lewis, Van Ijzendoorn, \& Permezel, 2011), which is neurobiologically defined as parent-infant co-regulation (Kommers, Oei, Chen, Feijs, \& Bambang Oetomo, 2016; Kommers, Broeren et al., 2017).

Co-regulation is when an organism influences the regulation of the internal environment of another organism through cue exchanging (Feldman, 2006). Cues are physiological and behavioral parameters such as touch, voice, scent, and heart rate (Feldman, Magori-Cohen, Galili, Singer, \& Louzoun, 2011). OT is an important cue modulator, as demonstrated by for instance its previously described influence on parturition and maternal behavior.

Cue exchange is suboptimal in preterm infants (Kommers et al., 2016). Both the physical immaturity and the early neonatal intensive care unit (NICU) environment with its bright lights, noise, painful procedures, and the mechanical barrier of the incubator, as well as the stress that parents experience during a NICU stay interfere with cueexchanging and thus with parent-infant co-regulation (Feldman, 2007; Kommers et al., 2016). This is an important issue, since suboptimal coregulation significantly impairs hormonal, epigenetic and neuronal development in preterm infants (Kommers et al., 2016). Fortunately,

\footnotetext{
Abbreviations: NICU, neonatal intensive care unit; KC, Kangaroo care; OT, oxytocin

* Corresponding author at: Department of Neonatology, Máxima Medical Centre, De Run 4600, 5504 DB, Veldhoven, The Netherlands.

E-mail address: Deedee.Kommers@mmc.nl (D. Kommers).
} 
these negative effects are reversible by bonding-increasing interventions such as Kangaroo care (KC) (Conde-Agudelo \& Díaz-Rossello, 2014; Kommers et al., 2016; Kommers, Broeren et al., 2017; Kommers, Joshi et al., 2017; Tessier et al., 1998).

KC refers to a period in which infants are placed in the prone position on a parent's naked chest. Parent and infant are in skin-to-skin contact, which facilitates cue exchanging, i.e. bonding. KC significantly reduces mortality even in extremely preterm infants (Conde-Agudelo \& Díaz-Rossello, 2014) and it is associated with important physiological benefits, including promoting quiet sleep, enhancing thermoregulation, and reducing crying or fussy behavior (Chwo et al., 2002). Furthermore, KC enhances breastfeeding, and parents indeed report an increased quality of bonding due to KC (Carbasse et al., 2013; CondeAgudelo \& Díaz-Rossello, 2014; Johnston et al., 2014; Ludington-Hoe, 2013). In addition to subjective parental reports on bonding, we hypothesized that this period of maximal cue exchanging might also be used to measure physiological aspects of bonding, like changes in OT. We reasoned that such a quantitative assessment of co-regulation in preterm infants could provide opportunities for enhancing the same (Kommers, Broeren et al., 2017).

In previous research, Cong et al. showed that $30 \mathrm{~min}$ of $\mathrm{KC}$ appeared to activate an OT release in the saliva of both mothers and fathers (Cong et al., 2015). Preterm infant OT was not investigated. We performed a study to assess the feasibility of measuring OT in preterm infants both before and during $\mathrm{KC}$, demonstrating that, when pooling the harvests of multiple saliva collections, OT could be measured unobtrusively in preterm infants (Kommers, Broeren et al., 2017). That feasibility study however did not examine the relation between KC and the salivary OT concentration.

In the current study, we investigated the effect of KC on the salivary OT concentration in preterm infants. In addition, we analyzed if relevant contextual correlates were of influence on the OT response, i.e. on whether OT increased or decreased.

\section{Materials and methods}

\subsection{Study population and design}

Approximately ten saliva samples had to be pooled in order to obtain sufficient saliva for measuring OT (Kommers, Broeren et al., 2017). To minimize variability in the pooled data set, we conducted a twin study. Exclusion criteria were clinical instability of any order resulting in contraindications for KC. Inclusion criteria were twins who were cardiorespiratory stable, born between 29 and 37 weeks of gestation, weighing over $1500 \mathrm{~g}$ and admitted to our hospital between December 2015 and January 2017. After this one-year recruitment period, an (interim) analysis was performed in agreement with the advice of the medical ethical committee, to investigate whether recruitment should continue due to the logistically challenging nature of the study design. Upon that agreement, they approved this study (NL54074.015.15) that was conducted according to the principles of the seventh revision of the Declaration of Helsinki in 2013. Based on the interim analysis, recruitment stopped January 2017. Written informed consent was obtained from the parents of each participant. In Table 1, patient metadata and correlates are shown for all participants together and when categorized according to their OT response.

After inclusion, saliva samples were collected from both twin-siblings twice a day, during five consecutive days. Hence, per twin, ten saliva samples were collected during baseline conditions (infants lying in bed or incubator in the absence of parental touch), and ten saliva samples during routine $\mathrm{KC}$ sessions after at least $30 \mathrm{~min}$ of $\mathrm{KC}$ had elapsed. To minimize the potential effect of feeding on the OT concentration, we aimed to keep the time between saliva collections and the last moment of feeding before that collection equal (on average, that time was $93 \mathrm{~min}$. (SD 55)). Saliva was collected using cotton swabs called Sorbettes (Salimetrics, California, USA). For a detailed
Table 1

Characteristics of all participants, and participants divided by their oxytocin response to $\mathrm{KC}$.

\begin{tabular}{|c|c|c|c|}
\hline Characteristics (mean, SD) & $\begin{array}{l}\text { Overall } \\
(\mathrm{N}=11)\end{array}$ & $\begin{array}{l}\text { OT-increase } \\
(\mathrm{N}=3)\end{array}$ & $\begin{array}{l}\text { OT-decrease } \\
(\mathrm{N}=8)\end{array}$ \\
\hline Birth weight (g) & $\begin{array}{l}1777.1 \\
(564.0)\end{array}$ & $1844.2(828.5)$ & $1752.1(442.5)$ \\
\hline Gestational age (days) & 226.9 (19.6) & $220.0(24.3)$ & $229.5(18.8)$ \\
\hline Weight during study (g) & $\begin{array}{l}2123.2 \\
(269.3)\end{array}$ & $2115.7(168.4)$ & $2126.0(309.0)$ \\
\hline KC duration (min) & $52.6(17.4)$ & $43.0(7.0)$ & $56.2(19.1)$ \\
\hline $\begin{array}{l}\text { Parent-infant interaction at } \\
\text { baseline }\end{array}$ & $0.7(0.5)$ & $0.8(0.4)$ & $0.7(0.5)$ \\
\hline $\begin{array}{l}\text { Parent-infant interaction } \\
\text { during KC }\end{array}$ & $2.2(0.5)$ & $1.9(0.4)$ & $2.4(0.5)$ \\
\hline $\begin{array}{l}\text { Parent-infant interaction } \\
\quad \text { increase }\end{array}$ & $1.5(0.4)$ & $1.1(0.3)$ & $1.7(0.3)$ \\
\hline Comfort state at baseline & $1.3(0.5)$ & $0.9(0.1)$ & $1.5(0.5)$ \\
\hline Comfort state during $\mathrm{KC}$ & $1.1(0.5)$ & $0.7(0.5)$ & $1.2(0.5)$ \\
\hline Comfort increase & $0.3(0.3)$ & $0.2(0.4)$ & $0.3(0.2)$ \\
\hline
\end{tabular}

Abbreviations: OT, oxytocin; SD, standard deviation; KC, Kangaroo care; Int., Interaction.

description of the collection procedure, we refer to Kommers et al. 2017 (Kommers, Broeren et al., 2017). After all samples had been collected, pooling of saliva samples was performed per twin: the harvests from all 10 collections at baseline per twin were pooled into one $1.5 \mathrm{ml}$ vial and the harvests from all 10 collections during KC per twin into another $1.5 \mathrm{ml}$ vial. Each vial thus contained either saliva from collections at baseline, or saliva from during $\mathrm{KC}$.

After each collection, nurses filled in a form (see the Appendix A) to collect metadata and correlates, including information about the duration of KC, the infant's state of comfort prior to and during the collections and the parent-infant interaction. Nurses are familiar with similar observation scores, but not formally trained for this research and these rating scales. In total, there were 22 different observers. Interobserver reliability was not calculated, since only one nurse was present during each collection and associated observation.

Two variables (the state of comfort and the parent-infant interaction) were measured using a Likert-scale that was developed during our previous feasibility study (Kommers, Broeren et al., 2017). In that feasibility study, the state of comfort was measured during the collection. In the current study, baseline comfort was established some minutes prior to and during the collections. A low score reflects a more comfortable state.

The difference in comfort state at baseline versus during $\mathrm{KC}$ was calculated as a proxy for the comforting effect of KC. For this, the score during KC was subtracted from the score at baseline. A higher score reflects an increase in comfort during $\mathrm{KC}$.

Additionally, the increase in parent-infant interaction from baseline to during $\mathrm{KC}$ was calculated by subtracting the interaction score at baseline from the interaction score during KC. A higher score reflected a better fit to the study protocol, i.e. absent parents during the collection at baseline and infant-parent interaction during KC.

\subsection{Saliva handling}

After finishing a saliva collection, nurses immediately placed the cotton swabs in tubes and transferred them to the laboratory for storage at $-20^{\circ} \mathrm{C}$. When all samples were collected, the tubes were allowed to reach room temperature for $30 \mathrm{~min}$. Subsequently, they were centrifuged at $4{ }^{\circ} \mathrm{C} 3000 \mathrm{r} / \mathrm{min}$ for five minutes, after which the saliva was pooled into vials. We immediately refroze the filled vials at $-20{ }^{\circ} \mathrm{C}$ in order to ship them to RIAgnosis (Munich, Germany) according to their protocols. There, saliva was analyzed according to the previously described procedure (Kagerbauer et al., 2013; Kommers, Broeren et al., 2017). Briefly, samples were extracted using LiChroprep Si60 (Merck, 
Hesse, Germany) which was heat-activated at $700^{\circ} \mathrm{C}$ for three hours. After evaporation using a SpeedVac High Capacity Concentrator (Thermo Scientific, Massachusetts, USA) $50 \mu$ of assay buffer was added. The oxytocin was then measured with a highly sensitive and specific radio-immuno assay, standardized and validated in human studies. The detection limit was in the $0.5 \mathrm{pg} / \mathrm{sample}$ range, the intraassay variation was less than $8 \%$ and the $<0.7 \%$ cross reactivity was considered negligibly small.

\subsection{Data analysis}

First, OT concentrations were subjected to the Shapiro-Wilk's test to investigate normalcy of distribution using the Statistical Package for the Social Sciences, 22nd edition (IBM Corp, Illinois, USA). Consecutively, either a paired $t$-test or a Wilcoxon signed-rank test was employed to examine the difference in OT concentration at baseline versus during KC. Effect size was calculated based on Cohen's d. Consecutively, vial pairs were divided into OT-increasing and OT-decreasing responses to examine correlates, similar to the maternal OT analysis in our feasibility study (Kommers, Broeren et al., 2017). Correlates were averaged per vial, i.e. the average comfort score of both infants across all days was calculated. Relevant correlates, as based on a previous feasibility study and Table 1 ( $>50 \%$ difference between the OT-increase and OTdecrease group), were displayed in cross tables with respect to their potential influence on OT-response. Correlates were binarized for this, using their average value as cut off point (e.g. a comfort state either above or below average). Finally, comfort at baseline was compared to comfort during KC to test whether this behavioral marker adequately captured the positive effect of KC and the correlation between comfort state and interaction scores was calculated.

\section{Results}

In total, 11 twins participated in this study (nine dichorionic and diamniotic, two monochorionic and diamniotic, 10 females and 12 males) yielding 22 vials filled with saliva. Of those 22 vials, 11 contained saliva from collections at baseline and 11 contained saliva from collections during KC. Both the OT concentration at baseline (mean $2.40 \mathrm{pg} / \mathrm{ml}$, SD $1.64 \mathrm{pg} / \mathrm{ml}$ ) and during $\mathrm{KC}$ (mean $1.39 \mathrm{pg} / \mathrm{ml}$, SD $0.57 \mathrm{pg} / \mathrm{ml}$ ) were normally distributed (Shapiro-Wilk scores were 0.13 and 0.73 respectively). During KC, the OT was lower than at baseline $(p=0.03)$ with a large effect size (Cohen's d 0.82).

Comfort scores at baseline and the increase in parent-infant interaction were identified as the most relevant correlates. The average comfort score at baseline was 1.3. This was lower in the OT-increasing group (0.9 (SD 0.1)), reflecting more comfort at baseline in this group than in the OT-decreasing group (1.5 (SD 0.5), Table 1). In none of the twins where OT increased, comfort was higher than average at baseline, as can be seen in Table 2 .

The average increase in parent-infant interaction was 1.5. This was lower in the OT-increasing group (1.1 (SD 0.3)) than in the OT-decreasing group (1.7 (SD 0.3)). In none of the twins where OT increased, parent-infant interaction increased more than average, as can be seen in Table 3.

Overall, babies appeared significantly more comfortable during KC (mean comfort score 1.1, SD 0.5) as opposed to baseline (1.3, SD 0.5,

Table 2

OT response to KC and comfort state at baseline.

\begin{tabular}{lll}
\hline & OT + & OT - \\
\hline More comfortable at baseline (comfort score $<1.3$ ) & 3 & 2 \\
Less comfortable at baseline (comfort score $\geq 1.3$ ) & 0 & 6
\end{tabular}

$\mathrm{OT}+$, vial pairs in which $\mathrm{OT}$ increased in response to $\mathrm{KC}, \mathrm{OT}-$, vial pairs in which OT decreased in response to KC.
Table 3

OT response to Kangaroo care and parent-infant interaction increase.

\begin{tabular}{lll}
\hline & OT + & OT - \\
\hline Parent-infant interaction increase below average $(<1.5)$ & 3 & 2 \\
Parent-infant interaction increase above average $(\geq 1.5)$ & 0 & 6 \\
\hline
\end{tabular}

$\mathrm{OT}+$, vial pairs in which OT increased in response to KC, OT -, vial pairs in which OT decreased in response to $\mathrm{KC}$

$95 \%$ CI $0.07-0.45, \mathrm{t}=3.10, p=0.01)$. The effect size of the difference in comfort states was medium (Cohen's d 0.51). The comfort state and interaction scores were coded independently, and they were uncorrelated (Pearson's $r<0.20$ ).

\section{Discussion}

In this study, we investigated the difference in salivary OT concentration in preterm infants during KC compared to baseline conditions in eleven twins. The main observation was that the OT concentration decreased during KC. In animals and adults, social behaviors such as licking and grooming and playful interactions have been associated with increases in OT (Feldman, Gordon, \& Zagoory-Sharon, 2011; Feldman et al., 2012; Kojima, Stewart, Demas, \& Alberts, 2012; Yoshida et al., 2009). However, as previously stated, OT responses are context dependent and both context and physiology differ greatly in preterm infants compared to adults, including differences in autonomic regulation with dominance of the sympathetic nervous system (Yiallourou, Witcombe, Sands, Walker, \& Horne, 2013). This dominance of the sympathetic nervous system in preterm infants is due to the later maturation of the parasympathetic nervous system and the chronic exposure to stress in the NICU (Carbajal et al., 2008; Eiselt, Clairambaultc, Mkdiguec, Peiranoe, \& Kauffmannd, 1993). As stressors are known to initiate an OT release (Jong et al., 2015; Ludington-Hoe, Cong, \& Hashemi, 2002; Neumann, 2002), we speculate that a decrease in OT during KC might be explained by higher baseline OT levels in preterm infants as a result of an overactive sympathetic system, actuating them to "ask" for co-regulation continuously: a "cry for help". Indeed, in our feasibility study the salivary OT concentrations at baseline were higher in preterm infants than in their mothers (Kommers, Broeren et al., 2017).

This hypothesis is further supported by the finding that babies tended to be less comfortable at baseline in the OT-decreasing vial pairs. In the one occasion where there was more discomfort during KC than during baseline conditions, OT increased. Moreover, in addition to less baseline comfort, a higher parent-infant interaction increase appeared associated with a decrease in OT. We speculate that parent-infant interaction during KC effectively reduced the high OT levels caused by the stressful environment.

These findings are strengthened by our previous study on heart rate variability (Kommers, Joshi et al., 2017). In that study, heart rate variability surprisingly decreased during $\mathrm{KC}$, as opposed to what would have been expected from adult studies on heart rate variability (Rajendra Acharya, Paul Joseph, Kannathal, Lim, \& Suri, 2006). This could be due to a switch in regulation from dominance of the sympathetic nervous system to dominance of more stable, myelinated branches of the vagal system in response to parental co-regulation during KC (Porges, 2001). KC is a period that is undisputedly associated with comfort throughout a NICU stay (Carbasse et al., 2013; Conde-Agudelo \& Díaz-Rossello, 2014; Johnston et al., 2014; Kommers et al., 2016; Ludington-Hoe, 2013; Ludington-hoe, Morgan, \& Care, 2008), as also supported by the increased comfort during KC compared to baseline reported in this study. It might thus be the case that in preterm infants, the OT release due to parental co-regulation during KC is less pronounced than the OT release due to the stressful baseline environment including parent-infant separation. Despite differences in the 
interpretation of parent-infant interaction scores, these findings are in agreement with our feasibility study. In that study, apart from one exception, OT also decreased when discomfort was high at baseline, but increased when discomfort was greater during KC compared to baseline. However, some substantial limitations need to be taken into account when interpreting these data.

First, the required sample size that was calculated based on the results in our feasibility study counted 21 twins and this study is based on an interim analysis of 11 twins (Kommers, Broeren et al., 2017). Recruitment stopped in January 2017, since the interim analysis yielded hypotheses generating results, but different study designs were needed to answer those hypotheses. The fact that significant changes in OT were found in this smaller sample size can be explained by a high correlation between OT measures at baseline and during KC, and smaller standard deviations compared to the feasibility study. The difference in standard deviations might be a result of the pooling of saliva, which was necessary to analyze OT, but it may introduce bias or an overestimated effect. One sibling might have intrinsically lower OT than the other sibling. Furthermore, interpreting data from an interim analysis requires taking into account the phenomenon that the found effect could have evened out when collecting the rest of the data (Pocock \& Hughes, 1989). Therefore, more research on the response of OT in preterm infants is necessary. For instance, this study was conducted in twins, assuming that this controls for some of the variability and thus reduces bias, since twin siblings shared the same pregnancy, parents, and environment during KC sessions. However, it would be interesting to replicate the study in singletons.

In the current study, the complete nursing team was involved, potentially generating inter-observer differences. Inter-coder reliability was not calculated, since only one nurse was present during each collection. However, nurses are very familiar with comfort scores and observing parent-infant interaction, and as such, multiple observers might increase the reliability of overall scores compared to a single observer. Therefore findings suggest that, rather than showing a unidirectional pattern, the peripheral OT response depends on baseline characteristics and context, as has been demonstrated in several previous studies (Clark et al., 2013; Feldman, Gordon, Schneiderman, Weisman, \& Zagoory-Sharon, 2010; Feldman, Gordon et al., 2011).

Such context dependent or varying results have led critics to raise the question whether peripheral OT is a valid marker, or in other words, whether peripheral OT concentrations indeed reflect central processes
(Kagerbauer et al., 2013). One of the reasons is that the hypothalamus is not the only site that produces oxytocin molecules; it is therefore possible that detected peripheral OT molecules come from a non-central or even a local origin (Gimpl \& Fahrenholz, 2001; Landgraf \& Neumann, 2004; Neumann \& Landgraf, 2012). Nonetheless, despite being an interesting issue, the origin of OT molecules is less relevant regarding our research question; even if the OT would have a local origin, they could still serve as a biological marker for a specific aspect of co-regulation. In addition, a positive association between central and peripheral OT was reported in a recent meta-analysis (Valstad, Alvares, Andreassen, Westlye, \& Quintana, 2017) and accumulating evidence shows that certain stimuli can cause a coordinated release of both central and peripheral oxytocin (Carter et al., 2007; Neumann \& Landgraf, 2012; Striepens et al., 2013). In preterm infants, having to ask for co-regulation due to a stressful environment could be a stimulus evoking both a central and peripheral oxytocin surge, resulting in high baseline salivary OT levels. KC could be a stimulus reducing that heightened OT level. More research is needed to confirm these findings.

\section{Conclusion}

The OT concentration in the pooled saliva of preterm infant twins decreased during $\mathrm{KC}$ compared to baseline conditions. We speculate that the stressful experience of parent-infant separation at baseline, actuating preterm infants to "ask" for co-regulation, results in higher baseline OT levels in several occasions. Future research is needed to investigate this hypothesis. Ideally, methods to collect more saliva in preterm infants or new sampling procedures will become available for such research, so that OT can be assessed in smaller volumes obtained from one saliva collection.

\section{Competing interests}

We have no competing interests to declare.

\section{Acknowledgements}

The authors would like to thank all participating families and all nurses for their cooperation, especially Astrid Osagiator, Floor Schmeitz and Marianne Nijssen.

\section{Appendix A}

Form for nurses. 


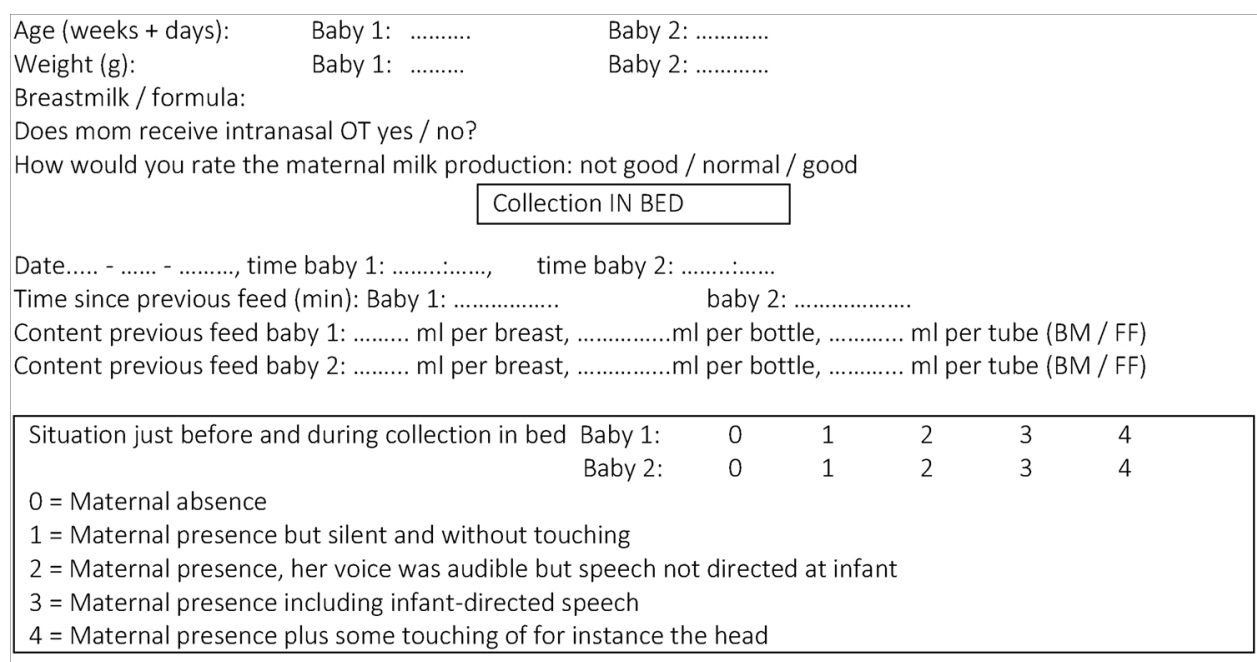

\begin{tabular}{|c|c|c|c|c|c|}
\hline State of comfort just before and during collection in bed Baby 1 : & 0 & 1 & 2 & 3 & 4 \\
\hline State of comfort just before and during collection in bed Baby 2 : & 0 & 1 & 2 & 3 & 4 \\
\hline \multicolumn{6}{|c|}{$0=$ Continuously normal, relaxed facial expression according to COMFORTneo } \\
\hline \multicolumn{6}{|c|}{1 = Totally relaxed facial expression for almost all of the time (minus 2 seconds) } \\
\hline \multicolumn{6}{|c|}{$2=$ Relaxed facial expression for most of the time (minus $<10$ seconds) } \\
\hline \multicolumn{6}{|c|}{$3=$ A lot of times a not totally relaxed expression ( $>10$ seconds $<1$ minute) } \\
\hline $4=A$ continuously intolerant expression or crying (abortion of th & & & & & \\
\hline
\end{tabular}

$$
\text { Collection DURING KANGAROO CARE (KC) }
$$

Date..... - ..... - ........, time baby $1:$............. time baby $2: \ldots \ldots \ldots \ldots \ldots$

Duration of KC ( $\mathrm{min})$ baby 1 : ........ baby 2 : .........

Time since previous feed (min): Baby 1: .................

Content previous feed baby $1:$........ ml per breast, .............ml per bottle, ........... ml per tube (BM / FF)

Content previous feed baby $2: \ldots \ldots \ldots . \mathrm{ml}$ per breast, .............ml per bottle, ........... $\mathrm{ml}$ per tube (BM / FF)

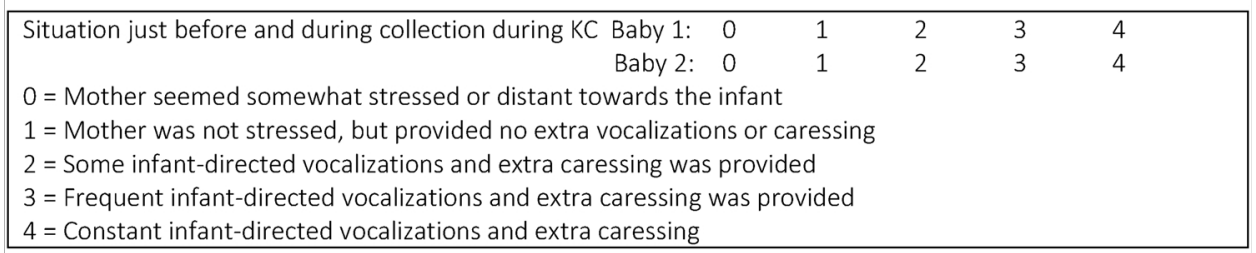

\begin{tabular}{|c|c|c|c|c|c|}
\hline State of comfort just before and during collection in bed Baby 1: & 0 & 1 & 2 & 3 & 4 \\
\hline State of comfort just before and during collection in bed Baby 2: & 0 & 1 & 2 & 3 & 4 \\
\hline \multicolumn{6}{|c|}{$0=$ Continuously normal, relaxed facial expression according to COMFORTneo } \\
\hline \multicolumn{6}{|c|}{$1=$ Totally relaxed facial expression for almost all of the time (minus 2 seconds) } \\
\hline \multicolumn{6}{|c|}{2 = Relaxed facial expression for most of the time (minus $<10$ seconds) } \\
\hline \multicolumn{6}{|c|}{$3=\mathrm{A}$ lot of times a not totally relaxed expression ( $>10$ seconds $<1$ minute) } \\
\hline $4=$ A continuously intolerant expression or crying (abortion of the & & & & & \\
\hline
\end{tabular}

\section{References}

Bartz, J. A., Zaki, J., Bolger, N., \& Ochsner, K. N. (2011). Social effects of oxytocin in humans: Context and person matter. Trends in Cognitive Sciences, 15(7), 301-309. http://dx.doi.org/10.1016/j.tics.2011.05.002.

Carbajal, R., Rousset, A., Danan, C., Coquery, S., Nolent, P., Ducrocq, S., ... Bréart, G. (2008). Epidemiology and treatment of painful procedures in neonates in intensive care units. JAMA: The Journal of the American Medical Association, 300(1), 60-70. http://dx.doi.org/10.1001/jama.300.1.60.

Carbasse, A., Kracher, S., Hausser, M., Langlet, C., Escande, B., Donato, L., ... Kuhn, P. (2013). Safety and effectiveness of skin-to-skin contact in the NICU to support neurodevelopment in vulnerable preterm infants. The Journal of Perinatal \& Neonatal Nursing, 27(3), 255-262. http://dx.doi.org/10.1097/JPN.0b013e31829dc349.

Carter, C. S., Pournajafi-Nazarloo, H., Kramer, K. M., Ziegler, T. E., White-Traut, R., Bello, D., ... Schwertz, D. (2007). Oxytocin: Behavioral associations and potential as a salivary biomarker. Annals of the New York Academy of Sciences, 1098, 312-322. http://dx.doi.org/10.1196/annals.1384.006.

Chwo, M.-J., Anderson, G. C., Good, M., Dowling, D. A., Shiau, S.-H. H., \& Chu, D.-M. (2002). A randomized controlled trial of early kangaroo care for preterm infants: Effects on temperature, weight, behavior, and acuity. The Journal of Nursing Research: JNR, 10.

Clark, C. L., St John, N., Pasca, A. M., Hyde, S. A., Hornbeak, K., Abramova, M., ... Penn, A. A. (2013). Neonatal CSF oxytocin levels are associated with parent report of infant soothability and sociability. Psychoneuroendocrinology, 38(7), 1208-1212. http://dx. doi.org/10.1016/j.psyneuen.2012.10.017.

Conde-Agudelo, A., \& Díaz-Rossello, J. L. (2014). Kangaroo mother care to reduce morbidity and mortality in low birthweight infants (review). Cochrane Database of Systematic Reviews, 4, 1-65. http://dx.doi.org/10.1002/14651858.CD002771.pub3.

Cong, X., Ludington-Hoe, S. M., Hussain, N., Cusson, R. M., Walsh, S., Vazquez, V., ... Vittner, D. (2015). Parental oxytocin responses during skin-to-skin contact in preterm infants. Early Human Development, 91(7), 401-406. http://dx.doi.org/10.1016/ 
j.earlhumdev.2015.04.012.

Eiselt, M., Clairambaultc, J., Mkdiguec, C., Peiranoe, P., \& Kauffmannd, F. (1993). Heartrate variability in low-risk prematurely born infants reaching normal term : A comparison with full-term newborns. Early Human Development, 32, 183-195.

Feldman, R. (2006). From biological rhythms to social rhythms: Physiological precursors of mother-infant synchrony. Developmental Psychology, 42(1), 175-188. http://dx.doi. org/10.1037/0012-1649.42.1.175.

Feldman, R. (2007). Parent-Infant synchrony biological foundations and developmental outcomes. Current Directions in Psychological Science, 16(6), 340-345.

Feldman, R., Gordon, I., Schneiderman, I., Weisman, O., \& Zagoory-Sharon, O. (2010). Natural variations in maternal and paternal care are associated with systematic changes in oxytocin following parent-infant contact. Psychoneuroendocrinology, 35(8), 1133-1141. http://dx.doi.org/10.1016/j.psyneuen.2010.01.013.

Feldman, R., Zagoory-Sharon, O., Weisman, O., Schneiderman, I., Gordon, I., Maoz, R., ... Ebstein, R. P. (2012). Sensitive parenting is associated with plasma oxytocin and polymorphisms in the OXTR and CD38 genes. Biological Psychiatry, 72, 175-181. http://dx.doi.org/10.1016/j.biopsych.2011.12.025.

Feldman, R., Gordon, I., \& Zagoory-Sharon, O. (2011). Maternal and paternal plasma, salivary, and urinary oxytocin and parent-infant synchrony: Considering stress and affiliation components of human bonding. Developmental Science, 14(4), 752-761. http://dx.doi.org/10.1111/j.1467-7687.2010.01021.x.

Feldman, R., Magori-Cohen, R., Galili, G., Singer, M., \& Louzoun, Y. (2011). Mother and infant coordinate heart rhythms through episodes of interaction synchrony. Infant Behavior \& Development, 34(4), 569-577. http://dx.doi.org/10.1016/j.infbeh.2011. 06.008.

Francis, D. D., Champagne, F. C., \& Meaney, M. J. (2000). Variations in maternal behaviour are associated with differences in oxytocin receptor levels in the rat. Journal of Neuroendocrinology, 12, 1145-1148. http://dx.doi.org/10.1046/j.1365-2826.2000. 00599.x.

Fuchs, A. R., Fuchs, F., Husslein, P., Soloff, M. S., \& Fernström, M. J. (1982). Oxytocin receptors and human parturition: A dual role for oxytocin in the initiation of labor. Science (New York, N.Y.), 215, 1396-1398. http://dx.doi.org/10.1126/science. 6278592.

Galbally, M., Lewis, A. J., Van Ijzendoorn, M., \& Permezel, M. (2011). The role of oxytocin in mother-infant relations: A systematic review of human studies. Harvard Review of Psychiatry, 19(1), 1-14. http://dx.doi.org/10.3109/10673229.2011. 549771.

Gimpl, G., \& Fahrenholz, F. (2001). The oxytocin receptor system: Structure, function, and regulation. Physiological Reviews, 81, 629-683.

Johnston, C., Campbell-Yeo, M., Fernandes, A., Inglis, D., Streiner, D., \& Zee, R. (2014). Skin-to-skin care for procedural pain in neonates. The Cochrane Database of Systematic Reviews, 1(1), CD008435. http://dx.doi.org/10.1002/14651858.CD008435.pub2.

Jong, T. R., de, Menon, R., Bludau, A., Grund, T., Biermeier, V., Klampfl, S. M., ... Neumann, I. D. (2015). Salivary oxytocin concentrations in response to running, sexual self-stimulation, breastfeeding and the TSST: The Regensburg Oxytocin Challenge (ROC) study. Psychoneuroendocrinology, 62, 381-388. http://dx.doi.org/ 10.1016/j.psyneuen.2015.08.027.

Kagerbauer, S. M., Martin, J., Schuster, T., Blobner, M., Kochs, E. F., \& Landgraf, R. (2013). Plasma oxytocin and vasopressin do not predict neuropeptide concentrations in human cerebrospinal fluid. Journal of Neuroendocrinology, 25(7), 668-673. http:// dx.doi.org/10.1111/jne.12038.

Kojima, S., Stewart, R. A., Demas, G. E., \& Alberts, J. R. (2012). Maternal contact differentially modulates central and peripheral oxytocin in rat pups during a brief regime of mother-pup interaction that induces a filial huddling preference. Journal of Neuroendocrinology, 24, 831-840. http://dx.doi.org/10.1111/j.1365-2826.2012. 02280.x.

Kommers, D., Oei, G., Chen, W., Feijs, L., \& Bambang Oetomo, S. (2016). Suboptimal bonding impairs hormonal, epigenetic and neuronal development in preterm infants, but these impairments can be reversed. Acta Paediatrica, International Journal of Paediatrics, 105(7), http://dx.doi.org/10.1111/apa.13254.

Kommers, D. R., Broeren, M. A. C., Andriessen, P., Oei, S. G., Feijs, L., \& Bambang
Oetomo, S. (2017). Pilot study demonstrates that salivary oxytocin can be measured unobtrusively in preterm infants. Acta Paediatrica, International Journal of Paediatrics, 106(1), http://dx.doi.org/10.1111/apa.13606.

Kommers, D. R., Joshi, R., van Pul, C., Atallah, L., Feijs, L., Oei, G., ... Andriessen, P. (2017). Features of heart rate variability capture regulatory changes during kangaroo care in preterm infants. The Journal of Pediatrics, 182, 92-98. http://dx.doi.org/10. 1016/J.JPEDS.2016.11.059 e1.

Landgraf, R., \& Neumann, I. D. (2004). Vasopressin and oxytocin release within the brain: A dynamic concept of multiple and variable modes of neuropeptide communication. Frontiers in Neuroendocrinology, 25(3), 150-176. http://dx.doi.org/10.1016/j.yfrne. 2004.05.001.

Levy, F., Kendrick, K. M., Goode, J. A., GuevaraGuzman, R., \& Keverne, E. B. (1995). Oxytocin and vasopressin release in the olfactory-bulb of parturient ewes - Changes with maternal experience and effects on acetylcholine, gamma- aminobutyric-acid, glutamate and noradrenaline release. Brain Research, 669, 197-206.

Ludington-hoe, S. M., Morgan, K., \& Care, K. (2008). A clinical guideline for implementation of kangaroo care with premature infants of 30 or more weeks' postmenstrual age. Advances in Neonatal Care, 8(3S), S3-S23.

Ludington-Hoe, S. M. (2013). Kangaroo care as a neonatal therapy. Newborn and Infant Nursing Reviews, 13, 73-75. http://dx.doi.org/10.1053/j.nainr.2013.03.004.

Ludington-Hoe, S. M., Cong, X., \& Hashemi, F. (2002). Infant crying: Nature, physiologic consequences, and select interventions. Neonatal Network: The Journal of Neonatal Nursing, 21(2), 29-36. http://dx.doi.org/10.1891/0730-0832.21.2.29.

Macdonald, K., \& Macdonald, T. M. (2010). The peptide that binds: A systematic review of oxytocin and its prosocial effects in humans. Harvard Review of Psychiatry, 18(1), 1-21. http://dx.doi.org/10.3109/10673220903523615.

Neumann, I. D. (2002). Involvement of the brain oxytocin system in stress coping: Interactions with the hypothalamo-pituitary-adrenal axis. Progress in Brain Research, 139, 147-162. http://dx.doi.org/10.1016/S0079-6123(02)39014-9.

Neumann, I. D., \& Landgraf, R. (2012). Balance of brain oxytocin and vasopressin: Implications for anxiety, depression, and social behaviors. Trends in Neurosciences, 35(11), 649-659. http://dx.doi.org/10.1016/j.tins.2012.08.004.

Pocock, S. J., \& Hughes, M. D. (1989). Practical problems in interim analyses, with particular regard to estimation. Controlled Clinical Trials, 10 (4 SUPPL. 1), 209-221. http://dx.doi.org/10.1016/0197-2456(89)90059-7.

Porges, S. W. (2001). The polyvagal theory: Phylogenetic substrates of a social nervous system. International Journal of Psychophysiology: Official Journal of the International Organization of Psychophysiology, 42(2), 123-146.

Rajendra Acharya, U., Paul Joseph, K., Kannathal, N., Lim, C. M., \& Suri, J. S. (2006). Heart rate variability: A review. Medical \& Biological Engineering \& Computing, 44(12), 1031-1051. http://dx.doi.org/10.1007/s11517-006-0119-0.

Striepens, N., Kendrick, K. M., Hanking, V., Landgraf, R., Wüllner, U., Maier, W., ... Hurlemann, R. (2013). Elevated cerebrospinal fluid and blood concentrations of oxytocin following its intranasal administration in humans. Scientific Reports, 3(1), 3440. http://dx.doi.org/10.1038/srep03440.

Tessier, R., Cristo, M., Velez, S., Giron, M., Ruiz-Palaez, J. G., Charpak, Y., ... Charpak, N. (1998). Kangaroo mother care and the bonding hypothesis. Pediatrics, 102(2), http:// dx.doi.org/10.1542/peds.102.2.e17 e17-e17.

Valstad, M., Alvares, G. A., Andreassen, O. A., Westlye, L. T., \& Quintana, D. S. (2017). The relationship between central and peripheral oxytocin concentrations: A systematic review and meta-analysis protocol. Neuroscience and Biobehavioral Reviews, 78, 117-124. http://dx.doi.org/10.1186/s13643-016-0225-5.

Yiallourou, S. R., Witcombe, N. B., Sands, S. A., Walker, A. M., \& Horne, R. S. C. (2013) The development of autonomic cardiovascular control is altered by preterm birth. Early Human Development, 89(3), 145-152. http://dx.doi.org/10.1016/j.earlhumdev. 2012.09.009.

Yoshida, M., Takayanagi, Y., Inoue, K., Kimura, T., Young, L. J., Onaka, T., ... Nishimori, K. (2009). Evidence that oxytocin exerts anxiolytic effects via oxytocin receptor expressed in serotonergic neurons in mice. The Journal of Neuroscience: The Official Journal of the Society for Neuroscience, 29, 2259-2271. http://dx.doi.org/10.1523/ JNEUROSCI.5593-08.2009. 